\title{
Preference of Suture Specifications in a Selected Periodontal and Implant Surgeries in Turkey
}

\author{
Cenker Zeki Koyuncuoglu $\quad$ Duygu Yaman ${ }^{1} \quad$ Gokhan Kasnak $^{1} \quad$ Korkud Demirel $^{1}$ \\ ${ }^{1}$ Department of Periodontology, Faculty of Dentistry, Istanbul Aydin \\ University, Istanbul, Turkey \\ Address for correspondence Cenker Zeki Koyuncuoglu, DDS, PhD. \\ Department of Periodontology, Faculty of Dentistry, Istanbul Aydin \\ University, Istanbul, Turkey (e-mail: zekikoyuncuoglu@aydin.edu.tr).
}

Eur J Dent 2019;13:108-113

\begin{abstract}
Objective Various suture materials and needles are now available for use in the dental surgery. The aim of this study was to determine the preference of suture materials among Turkish dentists by a dental survey.

Materials and Methods The survey was prepared and sent electronically to Turkish dentists through e-mail and/or Facebook. Dentists were asked to report their graduation year from dental school and their specialty if they have one. In addition, the type periodontal/implant operations and the frequency of those operations applied by them were questioned. The participants were to indicate their suture preferences for these procedures in a multiple-choice questionnaire.

Results Fifty-seven regular dentists, 49 periodontists, 22 oral surgeons, and 8 other specialists completed a self-administered survey. The majority of clinicians worked in private practice (77.9\%). Nonabsorbable sutures were the most preferred for all procedures except periodontal plastic surgery. In regenerative surgeries, monofilament, 5-0 diameter suture material on a reverse cutting, 3/8 circle needle was preferred. In addition, for mucogingival surgery, 5-0 diameter suture material on a reverse cutting and $3 / 8$ circle needle was favored. For dental implants, 4-0 diameter suture material on a reverse cutting and 3/8 circle needle was preferred. Monofilament and braided

Keywords

- implant surgeries

- periodontal operations

- suture types sutures were selected almost equally for implant operations.

Conclusions In periodontal and implant surgeries, dentists highly preferred the use of nonabsorbable sutures. In addition, the shape and diameter of needle had an important role in the selection of suture material. The present study's results may serve as a guide for the future studies.
\end{abstract}

\section{Introduction}

Wound closure is a key element for healing following surgical operations and important to promote favorable and successful healing while reducing complications such as infection. ${ }^{1,2}$ Sutures, surgical clamps, and adhesive agents are used for securing and stabilizing detached tissues for the subsequent satisfactory healing. ${ }^{3}$ Surgical clamps may not be suitable for routine oral surgery interventions due to the high cost and the failure to affect the closing forces. ${ }^{4}$ Cyanoacrylate tissue adhesives may be applied occasionally as an alternative to suturing. ${ }^{5-7}$ In addition, tissue adhesives have bacteriostatic and hemostatic properties and reduce the treatment time. ${ }^{8}$ However, some disadvantages of adhesives include insufficient adherence to wound margins, application problems, and prolonged healing times. These variables limit the use of adhesives. ${ }^{3}$ Although suturing is usually a time-consuming and technique-sensitive part of surgical procedures, it is the best available technique for ideal wound closure without destroying the physiological aspects of wound healing. ${ }^{9}$

Ideally, suture materials should be biocompatible and induce minimal tissue reactions while providing sufficient strength during the critical period of healing. These materials are classified as braided multifilament and 
monofilament or bioabsorbable and nonabsorbable. ${ }^{10}$ The needle and thread characteristics affect wound healing and surgical outcome. ${ }^{9}$ For instance, the silk sutures were tested against Teflon (polytetrafluoroethylene) in implant operations. Silk sutures showed less intraoperative handling and less patient discomfort. In addition, the latter was shown to have less plaque accumulation, but without a statistical difference. ${ }^{11}$ Leknes et al stated that braided silk sutures cause a more extensive inflammatory tissue reaction than monofilament sutures due to their ability to conduct bacterial migration into the flap. ${ }^{12}$ In periodontal surgery, 3/8 circular, reverse cutting, sharp needle sutures with $4-0,5-0$, or $6-0$ tread diameter are generally preferred to ensure optimum results through minimizing tissue trauma. ${ }^{3,13-15}$ Furthermore, not only the needle and thread characteristics but also the suturing technique and the surgical approach have an influence on the wound healing. Tavelli et al showed that the suturing technique has a significant role in the flap adaptation that might enhance the surgical outcome. ${ }^{16}$

There are many suturing materials now available in the dental market. However, the selection of suture material for periodontal or implant surgery is often based on personal choices rather than scientific data and has not been extensively investigated. The aim of this study was to determine the preference of suture materials among a group of dentists in Turkey by a dental survey.

\section{Materials and Methods}

\section{Study Design}

This study was conducted between March 2013 and July 2013. The study protocol was approved by the Istanbul Aydin University Ethics Committee (number: 238). Surveys (-Fig. 1) were prepared in Google Forms and were sent through Facebook (professional dentistry groups) and e-mail accounts to the dentists to increase participation.

Demographics of the participants were specified by professional experience (years of practice and practice setting) and the presence of a specialty.

The type and frequency of periodontal and implant operations reported by the dentists were recorded. The participants were asked to specify the choice of their suture type (absorbable or nonabsorbable, monofilament or braided multifilament, and thread diameter $[3-0,4-0,5-0,6-0$, and 7-0]), needle shape (circular shaped, reverse cutting, or cutting), and needle cutting edge preference in different operations such as periodontal surgeries (flap, guided tissue regeneration [GTR] operations), mucogingival surgeries (frenectomy, vestibuloplasty, free gingival graft [FGG], and

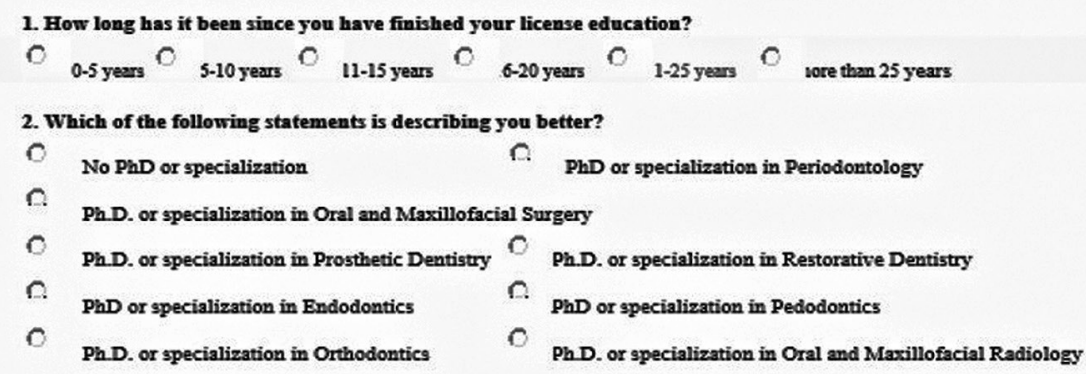

3. Which university did you graduate from?

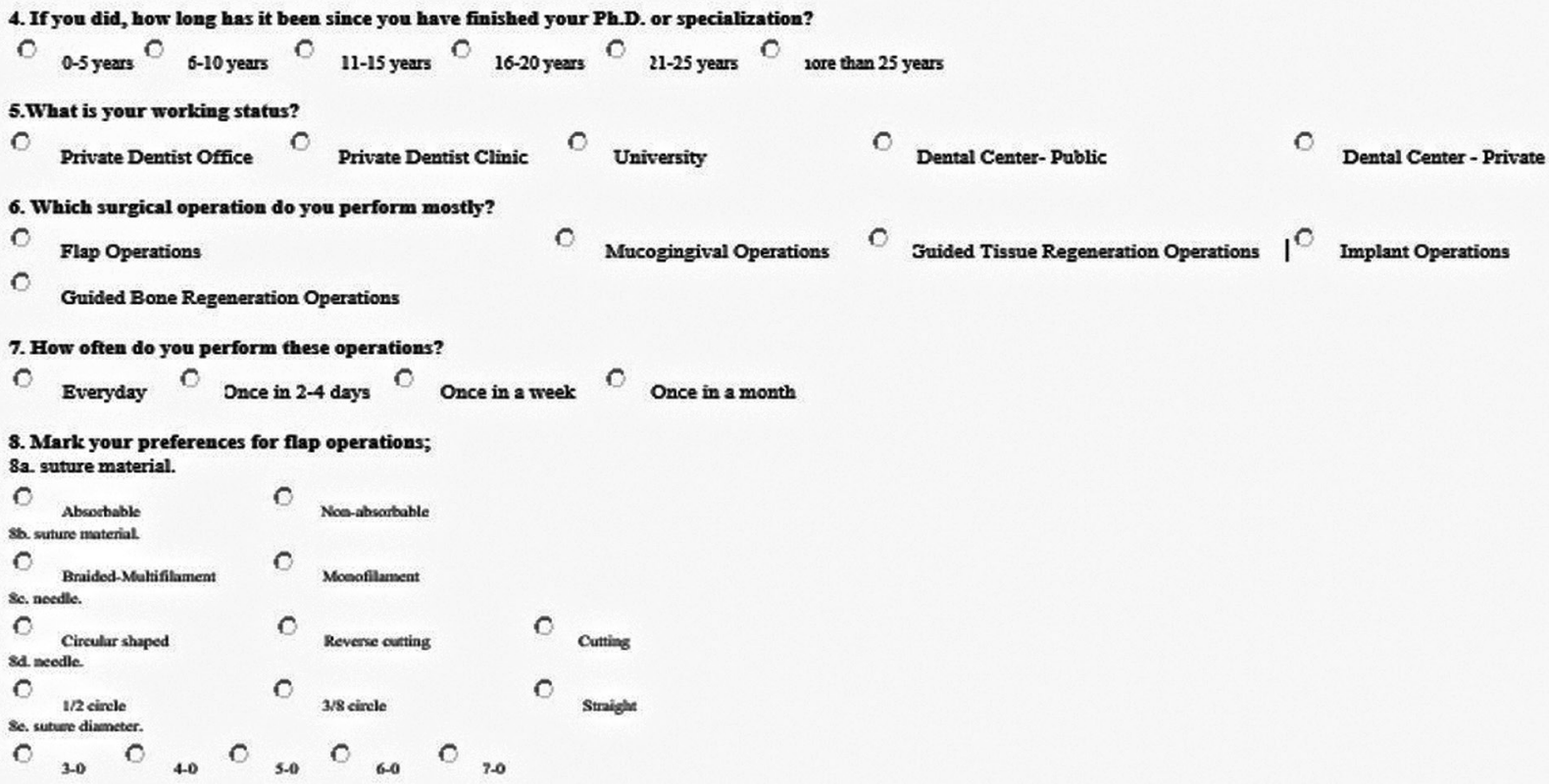

Fig. 1 The survey consists of 15 questions, and the first eight questions are shown. 
connective-tissue graft), and implant operations with or without guided bone regeneration (GBR).

\section{Statistical Analysis}

The statistical analysis was performed using the Statistical Package for the Social Sciences software (IBM Corp, released 2013, Version 22.0, Armonk, New York). The collected results were averaged (mean \pm standard deviation) for all parameters.

\section{Results}

In total, 136 participants completed the survey and $66.2 \%$ of the participants defined themselves as experienced clinicians in practice over 10 years. About $41.9 \%$ of the participants were general practitioners. Among the specialists, $62.6 \%$ were periodontists and $27.9 \%$ were oral surgeons. Approximately, $41.2 \%$ of the specialists reported having 5 or more years of experience. Only $22.1 \%$ of the clinicians worked at a university clinic or public hospital. About $42.6 \%$ of the participants reported that they perform only implant surgeries, whereas the percentage of doctors performing all five listed surgeries was $14 \%$. In total, $58.9 \%$ of the participants reported performing surgical interventions more than three times in a week. In the survey, no clinician selected the 7-0 suture diameter.
About $75.7 \%$ of the participants reported using nonresorbable suture material in flap surgery. Nearly $42.6 \%$ of the clinicians reported using only braided suture material and $41.2 \%$ used only monofilament. Only $8.1 \%$ reported to use both and the remaining dentists did not respond to this question. About $45.6 \%$ and $72.8 \%$ of them reported using reverse cutting needles and $3 / 8$ circle needles for flap surgeries, respectively. 4-0 and 5-0 diameter suture materials were preferred $52.2 \%$ for flap operations by the clinicians.

Nonresorbable and monofilament suture materials were highly preferred in GTR operations $(60.3 \%$ and $63.2 \%$, respectively). In these surgeries, the most selected diameter was $5-0$. Reverse cutting and $3 / 8$ circle needles were most preferred in GTR operations. Similarly, nonabsorbable, monofilament, 5-0 diameter material on a reverse cutting, and $3 / 8$ circle sutures were preferred in hard-tissue ridge augmentations.

Monofilament, 5-0 suture material on a reverse cutting, and 3/8 circle needle was favored for FGG, subepithelial connective-tissue grafts (SCTG), and frenectomy operations. Nonabsorbable and absorbable sutures were preferred almost equally for frenectomy and SCTG operations. However, nonresorbable sutures were more preferred in FGG operations.

For dental implant surgeries, 3-0, 4-0, and 5-0 diameter threads on reverse cutting, $3 / 8$ circle needles were preferred.

Table 1 Periodontal and dental implant operations versus suture preferences (absorbable or nonabsorbable, monofilament or braided multifilament, and diameter of the thread)

\begin{tabular}{|c|c|c|c|c|c|c|c|}
\hline Suture material & $\begin{array}{l}\text { Periodontal } \\
\text { flap, } \\
n(\%)\end{array}$ & $\begin{array}{l}\text { Guided tissue } \\
\text { regeneration, } \\
n(\%)\end{array}$ & $\begin{array}{l}\text { Frenectomy, } \\
n(\%)\end{array}$ & $\begin{array}{l}\text { Free } \\
\text { gingival } \\
\text { graft, } n(\%)\end{array}$ & $\begin{array}{l}\text { Connective } \\
\text { tissue graft, } \\
n(\%)\end{array}$ & $\begin{array}{l}\text { Dental } \\
\text { implant, } n \\
(\%)\end{array}$ & $\begin{array}{l}\text { Guided bone } \\
\text { regeneration, } \\
n(\%)\end{array}$ \\
\hline Absorbable & $22(16.2)$ & $30(22.1)$ & $59(43.4)$ & 42 (30.9) & $46(33.8)$ & $14(10.3)$ & $22(16.2)$ \\
\hline Nonabsorbable & $103(75.7)$ & $82(60.3)$ & $57(41.8)$ & $62(45.6)$ & $49(36.0)$ & $110(80.9)$ & $79(58.1)$ \\
\hline Both & $1(0.7)$ & $2(1.5)$ & $4(3.0)$ & $6(4.4)$ & $10(7.4)$ & $6(4.4)$ & $5(3.7)$ \\
\hline No response & $10(7.4)$ & $22(16.2)$ & $16(11.8)$ & $26(19.1)$ & $31(22.8)$ & $6(4.4)$ & $30(22.1)$ \\
\hline Braided & $58(42.6)$ & $23(16.9)$ & $52(38.2)$ & $36(26.5)$ & 27 (19.9) & $56(41.2)$ & $29(21.3)$ \\
\hline Monofilament & $56(41.2)$ & $86(63.2)$ & $61(44.9)$ & 72 (52.9) & $68(50.0)$ & $62(45.6)$ & $69(50.7)$ \\
\hline Both & $11(8.1)$ & $5(3.7)$ & $5(3.7)$ & $1(0.7)$ & $9(6.6)$ & $9(6.6)$ & $10(7.4)$ \\
\hline No response & $11(8.1)$ & $22(16.2)$ & $18(13.2)$ & 27 (19.9) & $32(23.5)$ & $9(6.6)$ & $28(20.6)$ \\
\hline $3-0$ & $17(12.5)$ & $16(11.8)$ & $16(11.8)$ & $6(4.4)$ & $6(4.4)$ & $29(21.3)$ & $13(9.6)$ \\
\hline $4-0$ & $31(22.8)$ & $25(18.4)$ & $44(32.4)$ & $15(11.0)$ & $10(7.4)$ & $34(25.0)$ & $26(19.1)$ \\
\hline $5-0$ & $28(20.6)$ & $53(39.0)$ & $47(34.6)$ & $42(30.9)$ & $40(29.4)$ & $30(22.1)$ & $33(24.3)$ \\
\hline $6-0$ & $6(4.4)$ & $19(14.0)$ & $11(8.0)$ & $23(16.9)$ & $26(19.1)$ & $1(0.7)$ & $5(3.7)$ \\
\hline $3-0+4-0$ & $12(8.8)$ & 0 & 0 & $3(2.2)$ & $2(1.5)$ & $14(10.3)$ & $8(5.9)$ \\
\hline $3-0+5-0$ & $4(3.0)$ & 0 & 0 & $1(0.7)$ & 0 & $2(1.5)$ & $1(0.7)$ \\
\hline $4-0+5-0$ & $12(8.8)$ & $1(0.7)$ & $1(0.7)$ & $9(6.6)$ & $4(2.9)$ & $11(8.1)$ & $10(7.4)$ \\
\hline $5-0+6-0$ & $3(2.2)$ & $1(0.7)$ & $1(0.7)$ & $8(5.9)$ & $10(7.4)$ & $3(2.2)$ & $9(6.6)$ \\
\hline $3-0+4-0+5-0$ & $6(4.4)$ & 0 & 0 & 0 & $2(1.5)$ & $3(2.2)$ & $3(2.2)$ \\
\hline $4-0+5-0+6-0$ & $5(3.7)$ & 0 & 0 & $1(0.7)$ & $3(2.2)$ & $1(0.7)$ & $2(1.5)$ \\
\hline $\begin{array}{l}\text { Other } \\
\text { combinations }\end{array}$ & $3(2.2)$ & 0 & 0 & 0 & 0 & $1(0.7)$ & 0 \\
\hline No response & $9(6.6)$ & $21(15.4)$ & $16(11.8)$ & $28(20.6)$ & $33(24.2)$ & $7(5.2)$ & $26(19.0)$ \\
\hline
\end{tabular}


Table 2 Periodontal and dental implant operations versus needle characteristics (needle cutting edge and shape)

\begin{tabular}{|l|l|l|l|l|l|l|l|}
\hline Needle & $\begin{array}{l}\text { Periodontal } \\
\text { flap, } \boldsymbol{n}(\%)\end{array}$ & $\begin{array}{l}\text { Guided tissue } \\
\text { regeneration, } \\
\boldsymbol{n}(\%)\end{array}$ & $\begin{array}{l}\text { Frenectomy, } \\
\boldsymbol{n}(\%)\end{array}$ & $\begin{array}{l}\text { Free } \\
\text { gingival } \\
\text { graft, } \boldsymbol{n}(\%)\end{array}$ & $\begin{array}{l}\text { Connective } \\
\text { tissue graft, } \\
\boldsymbol{n}(\%)\end{array}$ & $\begin{array}{l}\text { Dental } \\
\text { implant, } \\
\boldsymbol{n}(\%)\end{array}$ & $\begin{array}{l}\text { Guided bone } \\
\text { regeneration, } \\
\boldsymbol{n}(\%)\end{array}$ \\
\hline Circular shaped & $20(14.7)$ & $25(18.4)$ & $30(22.1)$ & $27(19.9)$ & $25(18.4)$ & $19(14.0)$ & $10(7.4)$ \\
\hline Reverse cutting & $62(45.6)$ & $56(41.2)$ & $50(36.8)$ & $53(39.0)$ & $50(36.8)$ & $61(44.9)$ & $59(43.3)$ \\
\hline Cutting & $33(24.3)$ & $34(25.0)$ & $30(22.1)$ & $21(15.4)$ & $24(17.6)$ & $40(29.4)$ & $30(22.1)$ \\
\hline Combinations & $11(8.1)$ & 0 & $9(6.5)$ & $7(5.1)$ & $5(3.7)$ & $9(6.6)$ & $11(8.1)$ \\
\hline No response & $10(7.4)$ & $21(15.4)$ & $17(12.5)$ & $28(20.6)$ & $32(23.5)$ & $7(5.2)$ & $26(19.1)$ \\
\hline $1 / 2$ circle & $19(14.0)$ & $12(8.8)$ & $14(10.3)$ & $25(18.4)$ & $16(11.8)$ & $21(15.4)$ & $12(8.8)$ \\
\hline $3 / 8$ circle & $99(72.8)$ & $90(66.2)$ & $90(66.2)$ & $88(64.7)$ & $80(58.8)$ & $97(71.3)$ & $88(64.7)$ \\
\hline Straight & $2(1.5)$ & $3(2.2)$ & $2(1.5)$ & $3(2.2)$ & $3(2.2)$ & $3(2.2)$ & $2(1.5)$ \\
\hline Combinations & $5(3.7)$ & $6(4.4)$ & $2(1.5)$ & 0 & $4(2.9)$ & $5(3.7)$ & $6(4.4)$ \\
\hline No response & $11(8.1)$ & $25(18.4)$ & $28(20.0)$ & $20(14.7)$ & $33(24.3)$ & $10(7.4)$ & $28(20.6)$ \\
\hline
\end{tabular}

Monofilament and braided sutures selected almost equally for implant surgeries. In addition, the nonabsorbable suture was favored. The use of absorbable sutures was more preferred for frenectomy (43.4\%) when compared to other listed surgical procedures, whereas for the implant surgery, nonabsorbable sutures were preferred (80.9\%).

Overall, clinicians showed a high preference for nonabsorbable sutures in all the procedures except periodontal plastic surgeries. In addition, reverse cutting $3 / 8$ circle needles were reported to be the most popular needle body type among all procedures listed. - Tables $\mathbf{1}$ and $\mathbf{2}$ illustrate the preference of sutures and needles, respectively.

\section{Discussion}

The present study was the first study about the preference of suture materials among dentists in Turkey. The results revealed that nonabsorbable sutures were more preferred, especially for dental implant, periodontal flap, and GTR operations. It has also been observed that reverse cutting and $3 / 8$ circle needles were the most frequently selected type.

The criteria of the suture material selection differ in dentistry from general medicine due to the effects of saliva, the existence of oral bacteria and their byproducts of metabolism, high tissue vascularization, and movement of the wound edges during mastication and speech. ${ }^{12,17,18}$ The penetration trauma results in the maximum tissue reaction at the third postsurgery day..$^{19}$ Absorbable or nonabsorbable sutures induce similar penetration trauma. ${ }^{20}$ However, it was reported that absorbable threads produce more tissue reaction. ${ }^{21,22}$ Natural absorbable suture (Catgut-collagen) is digested by proteolytic enzymes, whereas synthetic absorbable sutures (Polyglycolide, Polyglactin 910) are degraded by hydrolysis reaction. ${ }^{23}$ In an animal study, it was demonstrated that natural absorbable suture caused more severe soft-tissue reaction compared with synthetic ones. On the other hand, synthetic absorbable threads cause less severe reaction related to their inorganic structure, but their absorptions are rather inconvenient. ${ }^{7}$ In a recent study, the popularity of suture materials among clinicians at a postdoctoral periodontology program was evaluated. Absorbable sutures were preferred in the majority of periodontal surgeries such as osseous repositioned flap, free gingival or SCTG, and dental implant operations. ${ }^{18}$ On the contrary, dentists' choices in the present study demonstrated a high preference for nonabsorbable sutures in all the procedures except periodontal plastic surgeries ( - Table $\mathbf{1}$ ).

The oral cavity is naturally colonized by several bacteria series and the tissues are more exposed to the bacterial infections. The suture material is evaluated as a foreign body that increases microbial penetration into the wound edges, and this risk is affected by the capillarity of the suture thread. ${ }^{2}$ Oral fluids and microorganisms could diffuse through multifilament threads along suture fibers by capillary action. ${ }^{24}$ However, it has been reported that synthetic threads constitute a mild inflammatory tissue reaction than sutures of organic origin. ${ }^{19}$ In addition, Setzen and Williams demonstrated that absorbable and nonabsorbable multifilament sutures elicit a more severe tissue response than nonabsorbable monofilament sutures. ${ }^{25}$ It has been recently reported that the first choice between the suture materials should be the nylon ones and their removal should be carried out as early as possible. ${ }^{26}$ In this study, clinicians favored monofilament threads for GTR with materials such as graft or/and membrane, GBR procedures, and FGG and SCTG operations. In addition, in this survey, monofilament and braided sutures selected almost equally for implant surgeries and periodontal flap operations.

The commonly used sutures and surgical needles in oral surgery have different features such as design, the materials they are made from, stability, and capillarity of the used thread. ${ }^{2}$ Using a smaller diameter needle such as $6-0$ or $7-0$ for the wound closure may reduce the risk of tearing or traumatizing the soft tissue and improve the passive flap adaptation. ${ }^{27,28}$ The present study revealed that 5-0 threads were selected mostly in GTR, free gingival, or connective-tissue graft operations. In addition, 6-0 threads were chosen in these procedures. Recently, it has been pointed out in a meta-analysis study that preferring microsurgical techniques and using sutures with a smaller diameter than 5-0 were 
associated with the success of root coverage. ${ }^{29}$ Surprisingly, 3-0, 4-0, and 5-0 diameter threads were preferred almost equally in implant surgeries. A study conducted in the United States reported that 4-0 diameter thread was most preferred in the surgical procedures such as periodontal flap surgery, oral GBR procedures, and hard-tissue augmentations, whereas 5-0 diameter thread was favorably used in free gingival/connective-tissue graft procedures. Both 4-0 and 5-0 diameter threads were selected almost equally in implant operations and soft-tissue ridge augmentations. ${ }^{18}$

The reverse cutting needle is the most suitable for oral surgery as its advantage of preventing soft-tissue tear, especially in the thin oral mucosa. ${ }^{18}$ This type of needle has considerable advantages over the classical cutting needles. it is much stronger and more protective to tissue trauma/ laceration and minimization of the risk of overtightening causing ischemia. ${ }^{2}$ In the present study, reverse cutting needles were the most favored for the periodontal and implant operations. In addition, dentists preferred to use circular and cutting-shaped needles except for GBR operations. However, Maksoud et al stated that no circular shaped and almost no cutting needle types were selected among clinicians at a teaching institution in the United States. ${ }^{18}$

Straight needles are used in intradermal sutures and skin wounds in the maxillofacial region ${ }^{30}$ whereas, curved needles such as $1 / 2$ and $3 / 8$ curved are mostly used in oral surgical operations. ${ }^{2}$ In addition, the $3 / 8$ circle needle generally ensures optimal results for periodontal surgeries. ${ }^{3}$ The data of the present study confirmed that the most selected needle type was $3 / 8$ circle. On the other hand, straight needles were preferred in all procedures with small numbers.

The possibility of multiple replies to the survey and a limited number of the participants were the limitations of this study.

\section{Conclusions}

Several parameters guide dentists' suture selection in each clinical scenario such as the quality and thickness of the soft tissues, the design of the flaps, and the personal choice. Within the limitations of the present study, it can be concluded that nonabsorbable and monofilament sutures were highly preferred in all the periodontal and implant operations. In addition, reverse cutting and 3/8 curvature needles were reported to be the most popular needle body type among all procedures. Finally, while this study retrospectively surveyed dental practitioners, these practitioners based their responses on their recent practice patterns; a future study that asked dentists and/or dental specialists to record prospectively information pertaining to their suture material and technique selection based on would presumably provide more accurate data. For this purpose, a questionnaire, in which certain case definitions such as anatomical considerations of the operation site, systemic and oral hygiene status, and expectations of the patient are included, might help to clarify the choice reasons of suture materials and techniques by the dental practitioners.

\section{Financial Support and Sponsorship}

None.

\section{Conflicts of Interest}

None.

\section{References}

1 Kamann WA, Grimm WD, Schmitz I, Müller KM. Die chirurgische Naht in der Zahnheilkunde. Parodontologie (Berl) 1997;4:295-310

2 Siervo S. Suturing Techniques in Oral Surgery. 1st ed. Berlin, Germany: Quintessence Publication Co; 2008

3 Burkhardt R, Lang NP. Influence of suturing on wound healing. Periodontol 2000 2015;68(1):270-281

4 Meng MV. Reported failures of the polymer self-locking (Hem-o-lok) clip: review of data from the Food and Drug Administration. J Endourol 2006;20(12):1054-1057

5 Herod EL. Cyanoacrylates in dentistry: a review of the literature. J Can Dent Assoc 1990;56(4):331-334

6 Vargas G, Reger TB. An alternative to sutures. Plast Surg Nurs 2001;21(2):83-85

7 Muglali M, Ylmaz N, Inal S, Guvenc T. Immunohistochemical comparison of indermil with traditional suture materials in dental surgery. J Craniofac Surg 2011;22(5):1875-1879

8 Kumar MS, Natta S, Shankar G, Reddy SH, Visalakshi D, Seshiah GV. Comparison between silk sutures and cyanoacrylate adhesive in human mucosa-a clinical and histological study. J Int Oral Health 2013;5(5):95-100

9 Burkhardt R, Lang NP. Periodontal plastic microsurgery. In: Lang NP, Lindhe J, eds. Clinical Periodontology and Implant Dentistry. Oxford, UK: Munksgaard, Blackwell; 2008:1029-44

10 Edlich RF, Panek PH, Rodeheaver GT, Turnbull VG, Kurtz LD, Edgerton MT. Physical and chemical configuration of sutures in the development of surgical infection. Ann Surg 1973; 177(6):679-688

11 Pons-Vicente O, López-Jiménez L, Sánchez-Garcés MA, Sala-Pérez S, Gay-Escoda C. A comparative study between two different suture materials in oral implantology. Clin Oral Implants Res 2011;22(3):282-288

12 Leknes KN, Røynstrand IT, Selvig KA. Human gingival tissue reactions to silk and expanded polytetrafluoroethylene sutures. J Periodontol 2005;76(1):34-42

13 Thacker JG, Rodeheaver GT, Towler MA, Edlich RF. Surgical needle sharpness. Am J Surg 1989;157(3):334-339

14 Mathur A, Bains VK, Gupta V, Jhingran R, Singh GP. Evaluation of intrabony defects treated with platelet-rich fibrin or autogenous bone graft: a comparative analysis. Eur J Dent 2015;9(1):100-108

15 Agarwal SK, Jhingran R, Bains VK, Srivastava R, Madan R, Rizvi I. Patient-centered evaluation of microsurgical management of gingival recession using coronally advanced flap with platelet-rich fibrin or amnion membrane: a comparative analysis. Eur J Dent 2016;10(1):121-133

16 Tavelli L, Barootchi S, Ravidà A. et al. Influence of suturing technique on marginal flap stability following coronally advanced flap: a cadaver study. Clin Oral Invest 2019; 23(2):1641-1651

17 McCaul LK, Bagg J, Jenkins WM. Rate of loss of irradiated polyglactin 910 (Vicryl Rapide) from the mouth: a prospective study. Br J Oral Maxillofac Surg 2000;38(4):328-330

18 Maksoud M, Koo S, Barouch K, Karimbux N. Popularity of suture materials among residents and faculty members of a postdoctoral periodontology program. J Investig Clin Dent 2014;5(1):45-50

19 Selvig KA, Biagiotti GR, Leknes KN, Wikesjö UM. Oral tissue reactions to suture materials. Int J Periodontics Restorative Dent 1998;18(5):474-487 
20 Postlethwait RW, Willigan DA, Ulin AW. Human tissue reaction to sutures. Ann Surg 1975;181(2):144-150

21 Bridgens NK. A comparative study of surgical suture materials and closure techniques. J Am Osteopath Assoc 1983;82(9, Suppl):715-718

22 Greenwald D, Shumway S, Albear P, Gottlieb L. Mechanical comparison of 10 suture materials before and after in vivo incubation. J Surg Res 1994;56(4):372-377

23 Irvin TT. Wound Healing - Principles and Practices. London, UK: Chapman and Hall; 1981

24 Lilly GE, Armstrong JH, Salem JE, Cutcher JL. Reaction of oral tissues to suture materials. II. Oral Surg Oral Med Oral Pathol 1968;26(4):592-599

25 Setzen G, Williams EF III. Tissue response to suture materials implanted subcutaneously in a rabbit model. Plast Reconstr Surg 1997;100(7):1788-1795

26 Asher R, Chacartchi T, Tandlich M, Shapira L, Polak D. Microbial accumulation on different suture materials following oral surgery: a randomized controlled study. Clin Oral Investig 2019;23(2):559-565
27 Burkhardt R, Preiss A, Joss A, Lang NP. Influence of suture tension to the tearing characteristics of the soft tissues: an in vitro experiment. Clin Oral Implants Res 2008;19(3):314-319

28 Wachtel H, Schenk G, Böhm S, Weng D, Zuhr O, Hürzeler MB. Microsurgical access flap and enamel matrix derivative for the treatment of periodontal intrabony defects: a controlled clinical study. J Clin Periodontol 2003;30(6):496-504

29 Tavelli L, Barootchi S, Nguyen TVN, Tattan M, Ravidà A, Wang HL. Efficacy of tunnel technique in the treatment of localized and multiple gingival recessions: a systematic review and meta-analysis. J Periodontol 2018;89(9):1075-1090

30 Soni A, Narula R, Kumar A, Parmar M, Sahore M, Chandel M. Comparing cyanoacrylate tissue adhesive and conventional subcuticular skin sutures for maxillofacial incisions-a prospective randomized trial considering closure time, wound morbidity, and cosmetic outcome. J Oral Maxillofac Surg 2013;71(12):2152.e1-2152.e8 